\title{
Pandemia e teletrabalho no Brasil: aspectos gerais ${ }^{1}$
}

\author{
Pandemia and tele-work in Brazil: general aspects
}

\author{
BRUNA CASIMIRO SICILIANI² \\ bruna.siciliani@gmail.com \\ BRUNA DIER ${ }^{3}$ \\ LUCIANE CARDOSO BARZOTTO 4 \\ Icardoso@trt4.jus.br
}

GALILEU - REVISTA DE DIREITO E ECONOMIA - e-ISSN 2184-1845

Volume XXI $\cdot 1^{\text {st }}$ January Janeiro $-30^{\text {TH }}$ June Junho $2020 \cdot$ pp. 52-76

DOI: http://doi.org/10.26619/2184-1845.XXI.1.3

Submitted on March $27^{\text {th }}, 2020$. Accepted on June $4^{\text {th }}, 2020$

Submetido em 27 de Março, 2020 . Aceite a 4 de junho, 2020

SUMÁRIO I. Introdução. II. Teletrabalho antes da pandemia. III. Teletrabalho depois da pandemia. IV. Direitos fundamentais do teletrabalhador em tempos de pandemia. V. A importância da negociação coletiva. VI. Conclusão. VII. Índice bibliográfico.

\section{INTRODUÇÃO}

De acordo com a Organização Internacional do Trabalho - OIT, o COVID-19, também conhecido popularmente no Brasil como Coronavírus, vai acabar com até 195 milhões de empregos globalmente apenas no segundo trimestre de 2020. A partir de uma legislação emergencial de calamidade pública, o teletrabalho tem sido utilizado em vários países do mundo, em maior ou menor grau, como forma de manutenção do emprego, em função do isolamento social e confinamento necessários para evitar a disseminação do vírus. Esta inserção se dá num contexto de digitalização sempre maior no mundo do trabalho, no para-

1 O presente artigo é versão atual ampliada da publicação “Teletrabalho antes e depois da pandemia: a importância da negociação coletiva” na Revista Justiça do Trabalho, v. 37, 2020.

2 Doutoranda em Direito pela Universidade Federal do Rio Grande do Sul. Mestrado em Direito pela Universidade Federal do Rio Grande do Sul. Especialização em Direito do Trabalho pela Pontifícia Universidade Católica do Rio Grande do Sul.

3 Mestrado em Direito pela Universidade Federal do Rio Grande do Sul. Especialização em Direito do Estado pela Universidade Federal do Rio Grande do Sul.

4 Professora adjunta da Universidade Federal do Rio Grande do Sul e professora permanente do Programa de Pós-Graduação em Direto da UFRGS. Doutorado em Direito pela Universidade Federal do Paraná. Pós-doutorado pela Universidade de Edimburgo. Juíza do Tribunal Regional do Trabalho da $4{ }^{\text {a }}$ Região. 
digma da indústria 4.0, como o modelo de produção em que tudo está conectado, se comunica e é compartilhado.

De modo geral, o teletrabalho foi o principal meio adotado pelas empresas para tentar manter parte da sua capacidade produtiva no momento de isolamento do coronavírus. No entanto, é evidente que o seu impacto não foi igual nas diversas sociedades, por diversas razões: dificuldades para "controle de produtividade", estranhamento do teletrabalhor, dificuldades técnicas, econômicas, sociais, em razão da estagnação da produção do consumo de bens e serviços.

Além disso, existem profissões extremamente presenciais que impedem o uso do teletrabalho - e especial referem-se ao setor da saúde. Portanto, estamos diante muitas empresas que correm o risco fechar as portas de forma temporária e até definitiva, durante este estado de calamidade que dura até dezembro de 2020, no caso brasileiro.

Sobre o teletrabalho, a Reforma Trabalhista, Lei n.13.467/2017 acrescentou 05 (cinco) artigos na CLT. Na MP 927, alguns destes artigos foram relativizados enquanto durar o estado de calamidade pública, mediante a regulação do teletrabalho nos artigos $3 .^{\circ}, 4 .^{\circ}$ e $5 .^{\circ}$.

Ao que se compreende, diferentemente, de outras estratégias para o enfrentamento dos impactos da pandemia do Coronavírus, o teletrabalho não parece ser um fenômeno ocasional.

Verifica-se que o teletrabalho veio para se estabelecer e modificar as relações de trabalho. Se o seu tratamento antes era de exceção, agora está sendo a regra e, talvez, permaneça deste modo para algumas atividades. Empregadores que antes não visualizavam o teletrabalho como uma oportunidade, pois a presença dos seus empregados era a forma de controlar o desempenho e produtividade de seus trabalhadores, atualmente se veem na obrigação de se ajustar e apostar nas ferramentas tecnológicas para prosperarem com suas empresas e manter empregos.

Diante desse cenário, a negociação coletiva revela sua importância como instrumento eficaz para a regulamentação das relações trabalhistas em regime de teletrabalho devido ao uso dos meios telemáticos por elevado número de categorias profissionais. Embora não obrigatória, a participação do sindicato é bem vinda para a garantia dos direitos fundamentais dos trabalhadores que foram lançados no mundo do teletrabalho.

Por isso, neste curto artigo, por meio do método dedutivo e valendo-se de revisão bibliográfica, será analisado o regramento do teletrabalho, antes e depois da pandemia, no contexto da legislação brasileira ${ }^{5}$, para então tecer considerações acerca da relevância da negociação coletiva neste panorama.

5 No Brasil o Decreto Legislativo no 6, de 20 de março de 2020, do Congresso Nacional reconheceu o estado de calamidade pública. Seguiram-se as seguintes normas, até 7 de abril de 2020: Lei no 13.979, de 6 de fevereiro de 2020, Lei no 13.982, de 2 de abril de 2020, Decreto no 10.278, de 18 de março de 2020, Decreto n. ${ }^{\circ} 10.288$, de 22.3.2020, Decreto n. ${ }^{\circ} 10.289$ de 24.3.2020, Decreto n. ${ }^{\circ}$ 10.300, de 30.3.2020, Decreto n. ${ }^{\circ} 10.285$, de 20.3.2020, Decreto n. ${ }^{\circ}$ 


\section{TELETRABALHO ANTES DA PANDEMIA}

Precisamos situar o teletrabalho num contexto de economia do compartilhamento que se digitaliza cada vez mais ${ }^{6}$.

Mudanças de paradigma produtivo como se tem referido à da indústria 4.0 e gig economy se expressam no termo digitalização do mundo do trabalho.

Teletrabalho é uma das expressões da digitalização do mundo do trabalho, o qual se insere, atualmente neste contexto maior, da digitalização do mundo do trabalho. O teletrabalho pode se dar modernamente mediante crowdwork, o chamado trabalho da multidão, o qual expressa o trabalho digital tanto da forma o via aplicativos (sob demanda), como da forma on line, através de plataformas, em uma espécie de fragmentação de uma determinada atividade, a qual é desempenhada por micro tarefas fatiadas, divididas e distribuídas entre uma série de trabalhadores ${ }^{7}$. Mas também pode referir-se a qualquer trabalho feito mediante tecnologia da informação.

O que se observa no trabalho remoto e no trabalho tecnológico em geral é o problema da regulação insuficiente, ou ausência de fiscalização que tende a levar o trabalhador a um excesso de produtividade e talvez de esgotamento por se dar longe do controle físico do empregador ou tomador de serviços.

Em 2017, a Fundação Europeia para a Melhoria das Condições de Vida e de Trabalho e a Organização Internacional do o relatório sobre "trabalhando a qualquer hora, em qualquer lugar: os efeitos no mundo do trabalho" ${ }^{8}$. Ironicamente alguns referem que teletrabalho e trabalho com tecnologia, na revolução 4.0, como se denomina a revolução tecnológica, a exemplo do crowdworking e trabalho em plataformas, em diversos espaços e tempos, poderiam configurar o um trabalho a todo tempo e todo o lugar, expressando a exaustão dos trabalhadores tecnológicos neste macro cenário. Este relatório investiga a influência do trabalho móvel com recursos de tecnologia e meios informatizados no mundo laboral. $\mathrm{O}$

10.284, de 20.3.2020, Decreto n. ${ }^{\circ}$ 10.283, de 20.3.2020, Decreto n. ${ }^{\circ}$ 10.282, de 20.3.2020, Medida Provisória n. ${ }^{\circ} 924$, de 13.3.2020, Medida Provisória n. ${ }^{\circ}$ 925, de 18.03.2020, Medida Provisória n. ${ }^{\circ}$ 926, de 20.3.2020, Medida Provisória n. ${ }^{\circ}$ 926, de 20.3.2020, Medida Provisória n. ${ }^{\circ}$ 945, de 04.04.2020, Medida Provisória n. ${ }^{\circ}$ 930, de 30.03.2020, Medida Provisória n. ${ }^{\circ}$ 931, Medida Provisória n. ${ }^{\circ}$ 936, de 01.04.2020, Medida Provisória No 938, de 2 de abril de 2020, Medida Provisória no 944, de 3 de abril de 2020, Medida Provisória n. ${ }^{\circ}$ 946, entre outras que se sucederam.

6 RIFKIN, Jeremy - The zero marginal cost society: the internet of things, the collaborative commons, and the eclipse of capitalism. New York: Palgrave Macmillan. 2014.

7 BARZOTTO, L. C.; LANNER, M. B - Fraternidade e trabalho digital na Constituição da Organização Internacional do Trabalho. In: I Congresso Internacional, Interinstitucional e Interdisciplinar de Pesquisadores em Direito e Economia, 2019, Belo Horizonte. Belo Horizonte: Universidade Federal de Minas Gerais, 2019. Veja-se também a dissertação de Maíra Lanner. LANNER, Maíra Brecht - Trabalho decente em meio ambiente digital. 2019. 134 f. Dissertação (Mestrado). Curso de Direito, Universidade Federal do Rio Grande do Sul, Porto Alegre, 2019.

8 ORGANIZAÇÃO INTERNACIONAL DO TRABALHO E EUROFOUND - Relatório "Trabalhando a qualquer hora, em qualquer lugar: os efeitos no mundo do trabalho". [Consultado em: 26/07/2018]. Disponível em: http://www. ilo.org 
ritmo acelerado da aplicação de tecnologias para se trabalhar à distância está mudando o modelo tradicional da relação de trabalho em que o empregado se concentra na sede e na estrutura empresarial. Tal mudança pode vir a melhorar a harmonia entre a família, vida pessoal e profissional, como também atenuar o deslocamento trabalho/casa e, como ponto de vantagem, aumentar a produtividade do trabalhador. No entanto, há desvantagens acerca do teletrabalho como elevar o número de horas trabalhadas, e o isolamento de se trabalhar em casa.

De acordo com o relatório, as conclusões sobre os efeitos da tecnologia da informação e comunicação não passam uma mensagem univoca. Refletem ambiguidades e, a despeito do local de trabalho indicam efeitos inespecíficos e revelam a inexatidão das fronteiras entre a vida profissional e familiar. Porém, não sem nega que as tecnologias de informação e comunicação ajudam as pessoas a organizar o trabalho com mais flexibilidade e permitem que o trabalho possa ser realizado a qualquer momento e em qualquer local, ofertando certa autonomia no tempo de labor'.

O resumo executivo ${ }^{10}$ deste relatório analisa que as Tecnologias da Informação e Comunicação (TICS) são mais comuns entre gestores e administradores, sendo expressivo da mesma forma entre os trabalhadores de apoio administrativo e comerciais.

O que se observa é a ocupação digital se expandindo paulatinamente, com um desempenho notável na última década. Como elucida Ramalho ${ }^{11}$, o fenômeno do teletrabalho teve como suporte os progressos tecnológicos na área da informática e das telecomunicações e a sua difusão, desde a décadas de oitenta ${ }^{12}$ se fundamentou em razões econômicas e de gestão.

9 EUROFOUND - Trabalhar a qualquer hora, em qualquer lugar e seus efeitos no mundo do trabalho. [Consultado em: 26/07/2018]. Disponível em: https://www.eurofound.europa.eu

10 Cf. EUROFOUND - Trabalhar a qualquer hora, em qualquer lugar e seus efeitos no mundo do trabalho. [Consultado em: 26/07/2018]. Disponível em: https://www.eurofound.europa.eu. Importante trazer alguns dados como a incidência do uso das tecnologias da informação e comunicação, pois variam substancialmente, de $2 \%$ a $40 \%$ de todos os funcionários, dependendo da determinado país e a frequência com que os funcionários executam o uso das tecnologias. Em toda a União Europeia, estima-se que pelo menos um total de cerca de $17 \%$ empregados fazem o uso de tecnologias. Quando ocasionais as tecnologias da informação e comunicação, como telefonemas ou e-mails fora do escritório, o número sobe para cerca de $40 \%$ de todos os funcionários no Japão e nos EUA.

11 Cf. RAMALHO, Maria do Rosário Palma - Estudo de Direito do Trabalho. V. 1. Livraria Almedina, Coimbra: 2003, p. 197.

12 Alguns autores como Jack M. Nilles, indicam que o teletrabalho surgiu por volta de 1973, quando este autor desenvolveu seus estudos sobre política federal em relação à substituição do transporte pelas telecomunicações. Logo veio o resultado quando trabalhou no Desenvolvimento de Políticas Relativas à Substituição do Transporte pelas Telecomunicações, criando um conceito para tal nomenclatura que se chamou telecommuting, acompanhado depois por teleworking para descrever aplicações mais amplas. NILLES, Jack M - Fazendo do teletrabalho uma realidade: um guia para telegerentes e teletrabalhadores. Tradução Eduardo Pereira e Ferreira. São Paulo: Futura, 1997, p. 10. 
No Brasil ${ }^{13}$, a Reforma trabalhista mantém a distinção entre o teletrabalhador e o trabalhador a domicílio, optando por configurar o teletrabalho com espécie de contrato de trabalho subordinado ${ }^{14}$, com certas especificidades que são basicamente duas: exercício fora da empresa e com utilização de meios telemáticos.

Como expresso no artigo 75-B, Capítulo II-A da CLT ${ }^{15}$, "considera-se teletrabalho a prestação de serviços preponderantemente fora das dependências do empregador, com a utilização de tecnologias de informação e de comunicação que, por sua natureza, não se constituam como trabalho externo". O parágrafo único do referido artigo dispõe ainda que "o comparecimento às dependências do empregador para a realização de atividades específicas que exijam a presença do empregado no estabelecimento não descaracteriza o regime de teletrabalho".

Dessa forma, o estudo do teletrabalho após a Reforma Trabalhista, Lei n. 13.467/2017 da CLT, deve ser conjugado com outros dispositivos desta Consolidação, como por exemplo o art. $6 .^{\circ}$ da CLT, conferida pela Lei n. 12.551/2011, que alude sobre o trabalho realizado por meios telemáticos e informatizados de comando, controle e supervisão equivalendo-se ao trabalho subordinado, bem como o novo inciso III do art. 62 da CLT, que trata do não controle de jornada de trabalho do teletrabalhador ${ }^{16}$.

Por meio da reforma, fugiu-se da teoria da parassubordinação ${ }^{17}$, uma espécie de terceiro gênero, entre trabalho autônomo e subordinado, adotado na Itália, a qual possui como características a continuidade, a pessoalidade e a coordenação, ao invés da subordinação. Ou seja, não há hierarquia entre colaborador e tomador, deixando-se ao último certa autonomia quanto ao modo de prestar seu serviço. Portanto, no Brasil, não se adotou este meio-termo entre o trabalho autônomo e o trabalho subordinado, optando-se por classificar o teletrabalho na categoria de trabalho subordinado. ${ }^{18}$

13 FINCATO, Denise Pires -Teletrabalho na Reforma Trabalhista Brasileira. Revista Magister de Direito do Trabalho, n. ${ }^{\circ} 82$, Jan-Fev/2018, p. 58.

14 WINTER, Vera Regina Loureiro - Teletrabalho: Uma forma alternativa de emprego. São Paulo: LTr, 2005, p. 91.

15 BRASIL - Consolidação das Leis do Trabalho - Decreto-Lei n. 5.452, de $10^{\circ}$ de maio de 1943. [Consultado em: 25/05/2018]. Disponível em: http://www.planalto.gov.br

16 CARELI, Rodrigo - O teletrabalho. In: Resistência: aportes teóricos contra o retrocesso trabalhista. Coordenadores: Jorge Luiz Souto Maior, et alii. 1. ed. São Paulo: Expressão Popular: 2017, p. 333. O autor acredita que a inclusão dos teletrabalhadores nessas hipóteses elencadas é inconstitucional uma vez que a Constituição da República Federativa do Brasil de 1988 é expressa no sentido de que a duração do trabalho é limitada em oito horas diárias e 44 horas semanais (artigo $7^{\circ}{ }^{\circ}$ inciso XIII).

17 Cf. OLIVEIRA, Murilo Carvalho Sampaio - Relação de emprego, dependência econômica e subordinação jurídica: revisitando os conceitos - critérios de identificação do vínculo empregatício. Curitiba: Juruá, 2014, p, 72. Explica o autor que a pequena parcela de autonomia do trabalhador que é parassubordinado decorre do poder de organizar o seu trabalho de colaboração, o que afastaria a possível configuração da relação de emprego.

18 Cf. CAVALCANTE, Jouberto de Quadros Pessoa; JORGE NETO - Francisco Ferreira. Uma reflexão sobre a "Subordinação" como elemento essencial da relação de emprego. In: CLT - 70 anos de Consolidação: Uma 
O contrato de trabalho é norteado pelo consenso entre as partes, sendo desnecessárias, a princípio, quaisquer formalidades, conforme o caput dos artigos 442 e 443 da CLT. No entanto o contrato de teletrabalho é um contrato formal, como se verifica no art. 75-C caput da CLT.

Tal artigo dispõe que a modalidade do regime de teletrabalho deva constar expressamente no contrato individual de trabalho, especificando as atividades que serão desenvolvidas pelo teletrabalhador. Além do mais, poderá haver alteração entre os regimes desde que exista mútuo acordo entre empregador e empregado e que tal alteração conste em um aditivo contratual. Expressa a lei que tal novação para um regime presencial por imposição do empregador, seja realizada num prazo mínimo de 15 dias para ocorrer a transição e mediante um aditivo contratual.

$\mathrm{O}$ artigo 75-D da CLT ${ }^{19}$ prevê que o teletrabalhador, através de um contrato escrito, fique responsável pela aquisição, manutenção e fornecimentos dos equipamentos tecnológicos e da infraestrutura necessária e adequada à prestação do trabalho à distância. Observa-se que tal artigo é uma inovação nas relações de trabalho quanto ao ônus do empreendimento ${ }^{20}$, que em regra, é atribuído ao empregador no qual tem responsabilidade direta pelos riscos da atividade econômica, conforme o caput do art. $2 .^{\circ}$, da CLT $^{21}$.

$\mathrm{O}$ artigo 75-E prevê que o empregador instrua os empregados que trabalhem em regime de teletrabalho "quanto às precauções a tomar a fim de evitar doenças e acidentes de trabalho", determinando dessa forma que o empregado assine um termo de responsabilidade.

A escassa regulamentação do regime de teletrabalho encontrada somente nos artigos 75-A a 75-E não exime o empregador na aplicação das normas fundamentais de proteção ao empregado e, no que concerne ao empregado, este não se desonera de realizar a atividade de forma a respeitar o poder de comando do empregador, à luz do art. 7. ${ }^{\circ}$ da Constituição Federal de 1988.

Por fim, a expectativa do ordenamento jurídico trabalhista, ao ter inserido o teletrabalho no rol do artigo 611-A, inciso VIII, oportuniza aos envolvidos nessa relação ajustarem de forma mais real as condições de trabalho do teletrabalhador, mediante negociação

reflexão social, econômica e jurídica. Jouberto de Quadros Pessoa Cavalcante e Marcos Antônio Cesar Villatore (Organizadores). São Paulo: Atlas, 2013, p. 98.

19 BRASIL - Consolidação das Leis do Trabalho - Decreto-Lei n. 5.452, de $1 .^{\circ}$ de maio de 1943. [Consultado em: 25/05/2018]. Disponível em: http://www.planalto.gov.br.

20 Cf. SIQUEIRA, Rodrigo Espiúca dos Anjos - A duração do trabalho na Lei 13.467/2017. In: Reforma trabalhista na visão acadêmica. Gilberto Stümer e Leandro do Amaral Dorneles de Dorneles (Organizadores). Porto Alegre: Verbo Jurídico, 2018, p. 93 - 118.

21 BRASIL - Consolidação das Leis do Trabalho - Decreto-Lei n. 5.452, de $1 .^{\circ}$ de maio de 1943. [Consultado em: 25/05/2018]. Disponível em: http://www.planalto.gov.br 
coletiva $^{22}$. Para a Organização Internacional do Trabalho (OIT) $)^{23}$, o teletrabalho é uma alternativa viável para se conciliar o trabalho e a família, sendo assim desenvolvido graças ao rápido desenvolvimento das TICs (Tecnologias da Informação e da Comunicação), fazendo com que o teletrabalho cresça consideravelmente nos últimos anos. Como os estudos já mencionados no relatório da EUROFOUND, a OIT confirma que o labor telepresencial permite diminuição do custos da locomoção ao trabalho, ou mesmo a eliminação destes, tanto em termos financeiros como de tempo, permitindo a adaptação de horários de trabalho a tarefas domésticas e responsabilidades familiares. Para as empresas, o teletrabalho pode reduzir custos de espaço de escritório embora sua continuidade por longo tempo possa levar ao isolamento e a jornadas de trabalho muito extensas devido à ausência de uma separação clara entre o tempo de trabalho e o tempo livre.

A OIT não possui uma Convenção sobre teletrabalho, mas há uma compreensão geral de que a Convenção sobre trabalho a domicílio se aplicaria ao teletrabalhador.

Conforme a Convenção sobre o trabalho a domicílio de 1996, n. 177, a expressão trabalho em domicílio significa o trabalho que uma pessoa, designada como trabalhador em domicílio, realiza: (i) em sua casa ou em outras instalações que escolher, além das instalações de trabalho do empregador; (ii) em troca de remuneração; (iii) com o propósito de produzir um produto ou prestar um serviço de acordo com as especificações do empregador, independentemente de quem fornece o equipamento, materiais ou outros elementos utilizados, a menos que essa pessoa tenha o grau de autonomia e independência necessário ser considerado trabalhador independente ao abrigo da legislação nacional ou de decisões judiciais[...]. (Tradução nossa) ${ }^{24}$.

Ou seja, a definição do trabalhador à domicílio para OIT é diversalegislação brasileira, mas como ponto de identidade tem a equiparação no quesito de dependência ou subordinação.

22 Cf. STÜMER, Gilberto - Relações Coletivas e teletrabalho. In: IV Congresso Ibero-Americano de teletrabalho e Teleatividades. Porto Alegre: Magister, 2011, p. 73.

23 ORGANIZAÇÃO INTERNACIONAL DO TRABALHO - Notas da OIT, trabalho e família n.5: Alternativas que podem facilitar a conciliação entre o trabalho e a família. [Consultado em: 25/02/2018]. Disponível em: http:// www.ilo.org. As Notas da OIT sobre trabalho e família baseiam-se na série Work and Family Information Sheets do Programa sobre Condições de Trabalho e Emprego (TRAVAIL). Sua tradução e adaptação ao contexto da América Latina e do Caribe foram realizadas pelo Programa Regional de Gênero e Trabalho Decente. A adaptação para o português foi realizada no âmbito do projeto "Gender equality within the world of work", financiado pelo Governo Norueguês. Esta iniciativa teve a participação do Escritório da OIT-Lisboa.

24 ORGANIZAÇÃO INTERNACIONAL DO TRABALHO - Convenio sobre el trabajo a domicilio, 1996 (núm. 177). [Consultado em: 27/06/2019]. Disponível em: http://www.ilo.org (a) la expresión trabajo a domicilio significa el trabajo que una persona, designada como trabajador a domicilio, realiza: (i) en su domicilio o em otros locales que escoja, distintos de los locales de trabajo del empleador; (ii) a cambio de una remuneración; (iii) con el fin de elaborar un producto o prestar un servicio conforme a las especificaciones del empleador, independientemente de quién proporcione el equipo, los materiales o otros elementos utilizados para ello,a menos que esa persona tenga el grado de autonomía y de independencia económica necesario para ser considerada como trabajador independiente en virtud de la legislación nacional o de decisiones judiciales [...]. 
Ainda em termos de normativas gerais, a comunidade europeia constituiu uma comissão que propôs um relatório sobre a implementação do Acordo-Quadro sobre o teletrabalho, também conhecido como Acordo Marco Europeu, para estabelecer o seguinte: a) definir o conceito de teletrabalho para abranger uma variedade de novas formas de trabalho; e (b) estabelecer uma série de princípios gerais a serem observados pelos empregadores e trabalhadores que executam o teletrabalho. Esses princípios precisariam cobrir: a natureza voluntária do teletrabalho e o direito de retorno, garantia de manutenção do status do empregado, garantias de igualdade de tratamento, informações a serem fornecidas ao teletrabalhador, cobertura de custos pelo empregador, garantia de treinamento específico, proteção no domínio da saúde e segurança, expediente, protecção da privacidade e protecção de dados pessoais, manter contato com a empresa, direitos coletivos dos teletrabalhadores, acesso ao teletrabalho. (Tradução nossa) ${ }^{25}$.

A comissão ainda considerou três fatores como essenciais na definição do conceito de teletrabalho como o desempenho do trabalho à distância e a utilização da tecnologia da informação e transmissão eletrônica de dados. Além disso, analisou se a atividade do trabalhador é de forma estável, com alguma permanência ou continuidade no tempo. E, por último, se o teletrabalhador devia estar numa relação de trabalho.

A intenção da comissão era a de fornecer uma base para a discussão para futuramente fazer ajustes alinhados com o desenvolvimento tecnológico que possibilitassem a inclusão de novas formas de trabalho.

Assim, os parceiros sociais europeus em sua cláusula 2 do Acordo-Quadro definiram o conceito de teletrabalho como:

O teletrabalho é uma forma de organização e/ou realização de trabalhos, utilizando tecnologia da informação, no contexto de um contrato/ relação de traba-

25 COMISSÃO DAS COMUNIDADES EUROPEIAS - Confederação Europeia dos Sindicatos (CES) a Confederação das Empresas Europeias (UNICE), o Centro Europeu das Empresas com Participação Pública e das Empresas de Interesse Económico Geral (CEEP); Associação Europeia de Artesanato, Pequenas e Médias Empresas (UEAPME). Relatório sobre a implementação do Acordo-Quadro sobre o Teletrabalho de 16 de julho de 2002. [Consultado em: 28/04/2020]. Disponível em: http://repertoriojuslaboral.blogspot.com. (a) defining the concept of telework to cover a variety of new forms of work; and (b) laying down a number of general principles to be observed by employers and workers performing telework. These principles would need to cover: - the voluntary nature of telework and the right to return; - a guarantee of maintenance of employee status; - guarantees of equal treatment; information to be provided to the teleworker; - coverage of costs by the employer; - a guarantee of specific training; - protection in the field of health and safety; - working time; - protection of privacy and protection of personal data; - keeping in contact with the firm; - collective rights of teleworkers;- access to telework. 
lho, onde o trabalho, que também pode ser realizado nas instalações do empregador, é realizado fora dessas instalações numa base regular. (Tradução nossa) ${ }^{26}$.

Portanto, ao examinar as normativas europeias entende-se que o Brasil não fica distante das mesmas, sendo que, em recente pesquisa ${ }^{27}$, a SAP Consultoria em recursos humanos em parceria com a SOBRATT - sociedade brasileira de teletrabalho e teleatividades, mostrou que do ano de 2016 até 2018 , houve um crescimento de $22 \%$ das empresas que adotaram o teletrabalho.

Porém, num contexto de pandemia, muitas destas orientações europeias estão sendo flexibilizadas, e no Brasil, a alteração contratual passou ser determinada pelo empregador, como se passa a analisar, como forma de manutenção do emprego e renda.

\section{TELETRABALHO DEPOIS DA PANDEMIA}

Visando evitar as demissões e amenizar o impacto econômico e social, o governo brasileiro lançou a Medida Provisória 927/2020, a qual elenca soluções para os empresários enfrentarem a pandemia. Portanto, ainda estamos vivendo o teletrabalho no período de calamidade pública que foi declarado até o final de 2020.

Aqui a crítica a esta medida provisória é no sentido que o Estado se retira num primeiro momento da manutenção do emprego e lança para o empregador os mecanismos do próprio contrato, via interrupção das atividades, pensando-se estritamente na manutenção relação de emprego e da renda do trabalhador, como um ônus para as empresas. Isso, num primeiro momento assustou os pequenos negócios e empresas, os quais representam $60 \%$ da economia brasileira.

26 COMISSÃO DAS COMUNIDADES EUROPEIAS - Confederação Europeia dos Sindicatos (CES) a Confederação das Empresas Europeias (UNICE), o Centro Europeu das Empresas com Participação Pública e das Empresas de Interesse Económico Geral (CEEP); Associação Europeia de Artesanato, Pequenas e Médias Empresas (UEAPME). Relatório sobre a implementação do Acordo-Quadro sobre o Teletrabalho de 16 de julho de 2002. [Consultado em: 28/04/2020]. Disponível em: http://repertoriojuslaboral.blogspot.com Telework is a form of organizing and/or performing work, using information technology, in the context of an employment contract/ relationship, where work, which could also be performed at the employer's premises, is carried out away from those premises on a regular basis.

Importante destacar que o relatório afirma que a definição de teletrabalho escolhida pelos parceiros sociais europeus exclui claramente o teletrabalho independente, que está fora do âmbito dos parceiros sociais. Por conseguinte, as medidas nacionais de execução não abordam a situação dos trabalhadores independentes. O risco inerente a essa abordagem é que, ao concordar com o teletrabalho, ex-funcionários possam ser encorajados a se tornarem autônomos e, com isso, perderem os direitos e a proteção concedidos pela legislação trabalhista geral e pelo Acordo-Quadro. Isto parece ser confirmado pela evidência de um alto índice de trabalho autônomo entre os teletrabalhadores em vários países.

27 SAP CONSULTORIA EM RECURSOS HUMANOS - Pesquisa Home Office Brasil 2018. [Consultado em: 08/01/2019]. Disponível em: https://sapconsultoria.com.br 
Ou seja, o Estado, em lugar de adotar as medidas para solucionar a crise financeira, optou por transferir a tomada de decisão em questões tão críticas para os particulares, como medida de austeridade e enfrentamento da crise. ${ }^{28}$ Após esta Medida Provisória o Estado brasileiro entrou em jogo, pela MP 936 de 1/04/2020, garantindo a participação sua com aporte financeiro em caso de suspensão das atividades.

Porém, nos deteremos na análise da MP 927, de 22 de março de 2020, a qual elenca o teletrabalho como hipótese de manutenção de emprego e renda.

Durante o período de calamidade pública, num contexto de força maior, o art. $3^{\circ}$ da $\mathrm{MP}$ 927 estabelece diversas medidas para minimizar os efeitos econômicos e tentar preservar o emprego. Dentre elas figura o teletrabalho.

Nos atentaremos apenas à medida do teletrabalho, recordando que a palavra medida refere a um tipo de legislação muito próxima a administrativa, mediante a qual se realizam políticas públicas. Por isso, sendo uma legislação feita às pressas possui algumas imprecisões que devem ser complementadas à luz das normas anteriores sobre teletrabalho, as quais, por sua vez também são criticadas por excesso de lacunas. ${ }^{29}$

Alterando a regra do art. 468 da CLT, no sentido da novação contratual bilateral, o art. $4{ }^{\circ}$ da MP 927 permite que o empregador mude de forma unilateral, ou seja pelo jus variandi do empregador, o regime de trabalho presencial para o teletrabalho.

Apesar da técnica do artigo, parece que o legislador regulou o teletrabalho como gênero de trabalho remoto e à distância. Convém lembrar que home office é modalidade de teletrabalho, desde que o profissional realize qualquer tipo de atividade intelectual e utilize os sistemas de informação e comunicação. Neste sentido, se distingue de um trabalho à domicílio que é o realizado por costureiras, por exemplo.

Ainda temos, nos diversos parágrafos do artigo quarto, a seguintes medidas de teletrabalho trazidas pela MP 927, sobre as quais teceremos rápidos comentários ${ }^{30}$ :

O parágrafo primeiro distingue o teletrabalho de outro trabalho externo, aquele, em tese, feito sem controle de jornada. Portanto, o teletrabalho da legislação emergencial da MP é localizado, via de regra, pelo que se observa, na residência ou domicílio do empregado, mantendo a orientação do art.75 da CLT.

O parágrafo segundo prevê o ajuste rápido entre empregado e empregador para iniciar o regime de teletrabalho em 48 horas, o que pode ser feito com meios telemáticos.

28 FERREIRA, António Casimiro - Sociedade da austeridade: e direito do trabalho de exceção. Porto: Vida Económica, 2012.

29 Neste sentido, um belo exemplo de legislação é o Código do Trabalho de Portugal que traz o teletrabalho regulamentado nos art.165 a 171.

30 MIZIARA, Raphael; UMBERTO, Antonio; COELHO, Fabiano; GASPAR, Danilo - Medida Provisória 927 de 2020 : comentários artigo por artigo. São Paulo: Revista dos Tribunais. Thomson Reuters, 2020, p. 121. 
O parágrafo terceiro permite que o empregado ajuste por aditivo contratual como serão ressarcidos os seus custos, a título indenizatório.

O parágrafo quarto prevê que, enquanto não forem instalados os equipamentos, pela ausência de adaptação do meio ambiente de trabalho, o empregado fica à disposição do empregador, o que significa que, mesmo sem trabalho, ele tem direito ao salário pela interpretação do art. 4 da CLT. Estas tratativas devem ser formalizadas em 30 dias. Seria interessante que a empresa destinasse uma ajuda de custo para indenizar o uso de equipamentos e gastos com internet, o que um acordo coletivo se ocupasse disso.

$\S 5 .^{\circ}$ O tempo de uso de aplicativos e programas de comunicação fora da jornada de trabalho normal do empregado não constitui tempo à disposição, regime de prontidão ou de sobreaviso, exceto se houver previsão em acordo individual ou coletivo.

A redação do parágrafo quinto parece confusa, visto que, por certo momento, encaminha que o empregado em teletrabalho não tenha controle de jornada, mas, por outro lado, a lei indica que há controle e limita que o empregado exija horas extras de prontidão ou de sobreaviso.

O artigo $5 .^{\circ}$ da MP 927 permite a adoção do regime de teletrabalho para estagiários e aprendizes. No Brasil o contrato de aprendizagem diz respeito a um contrato de trabalho especial, focado na aprendizagem profissional definido no art.428 da CLT. Já a na Lei n. ${ }^{\circ}$ 11.788/08 define o estágio como ato educativo, focado na experiência profissional como complemento curricular de cursos. Todos estes trabalhadores podem exercer o teletrabalho e na eventual impossibilidade de desenvolver a ocupação costumeira, subsiste um dever da empresa de fornecer espécie de treinamento, a ser feito de forma à distância, segundo nossa interpretação, aproximando o estagiário e o aprendiz de atividades de formação, por aplicação analógica ao artigo 16 da MP 927, norma que refere treinamentos em saúde e segurança.

Em síntese, para possibilitar a rápida adoção dessa modalidade de trabalho, a MP 927 dispensou a exigência de registro prévio no contrato de trabalho para alterações do regime de trabalho presencial para teletrabalho ou seu retorno ao presencial, reduziu a antecedência mínima de notificação do empregado para 48 horas para tais modificações, as quais passaram a poder ser definidas unilateralmente pelo empregador, além de permitir sua aplicação a estagiários e aprendizes, sem a necessidade do sindicato participar deste ajuste. Ainda, como se verifica do texto da lei o empregador emprestará os equipamentos ao empregado e prevê certo reembolso das despesas. Fala-se em jornada normal do trabalho, motivo pelo qual se pressupõe que o trabalho seja de 8 horas, para aqueles que foram colocados em 
trabalho remoto, por interpretação conforme o art. $7 .^{\circ}$, inciso XIII da Constituição Federal de 88. Pela redação confusa dos parágrafos do art. $4 .^{\circ}$ da $\mathrm{MP}$, discute-se a possibilidade ou não de controle de horário do teletrabalhador. Isso é importante porque a MP 936 permite que o empregado receba um benefício se reduzir salário e jornada, medida para a qual não fica excluído o teletrabalhador.

Além das medidas legislativas, até 21.08.2020, foram celebrados ao todo 625 negociações coletivas sobre teletrabalho no Brasil. A consulta foi realizada no Sistema de Negociações Coletivas de Trabalho - MEDIADOR ${ }^{31}$ do Ministério realizadas entre 11.03.2020 até 21.08.2020, mencionando a palavra teletrabalho. $\mathrm{O}$ número se revela importante, pois demonstra o avanço das negociações coletivas para regulamentar esta nova forma de trabalho após o início da pandemia.

Analisam-se algumas cláusulas negociais na seqüência: a) algumas mencionam que o regime de teletrabalho poderá ser estendido para os estagiários e aprendizes, conforme já trazia a previsão legal contida no artigo; b) outras adotam flexibilização do período de transição previsto no $\S 2 .^{\circ}$ do art. $75-\mathrm{C}$ da CLT no caso de teletrabalho iniciado em razão da pandemia: o retorno do empregado poderá ocorrer imediatamente após a requisição do empregador, sem a necessidade de se aguardar o período mínimo de quinze dias; c) várias negociações trazem regras atinentes ao uso da imagem do empregado e acidentes de trabalho, como se transcreve:

“c) A EMPRESA deverá instruir os empregados, de maneira expressa e ostensiva, quanto às precauções a tomar a fim de evitar doenças e acidentes de trabalho, a partir de quando se presumirá que as doenças e os acidentes, que somente poderiam ter origem no descumprimento dessas instruções, foram concebidos ou agravados por culpa exclusiva do empregado, independentemente de prova de fiscalização por parte do empregador, impedido de adentrar à casa do empregado pela garantia constitucional da inviolabilidade de domicílio.

d) O empregado deverá assinar termo de responsabilidade comprometendo-se a seguir as instruções fornecidas pela empresa.

e) Fica ajustado que a visualização das imagens capturadas em eventual chamada por vídeo com o empregado, equivalem a uma reunião pública, ocorrida no interior da empresa, podendo ser gravada e utilizada para fins lícitos de

31 MINISTÉRIO DO TRABALHO E EMPREGO. Sistema de Negociações Coletivas de Trabalho - MEDIADOR. Disponível em: http://www3.mte.gov.br/sistemas/mediador/. Acesso em: 22 agosto 2020

Estes dados podem sofrer revisões futuras devido à incorporação de negociações coletivas que ainda não haviam sido depositados no sistema à época da consulta. 
exercício do poder empregatício, sendo dever do empregado, livrar o ambiente filmado de acontecimentos íntimos e de sua vida privada.

f) A aceitação de chamadas por vídeo dependerá de ato próprio do empregado, ficando proibida a ativação remota da câmara pelo empregador para qualquer finalidade".

Da análise dos trechos transcritos, verifica-se que direitos com base em direitos constitucionais já assegurados ao teletrabalhador aparecem nas normas coletivas e inclusive direitos novos que estão contemplados na LGPD, Lei n. 13.709/2018, atinentes à imagem e regulamentos que dizem respeito à vida privada.

Tanto a CLT como a MP 927/20 deixaram ao mútuo consentimento ou ao empregador a decisão de adotar o teletrabalho. No entanto diversas normas coletivas têm regulado a possibilidade de tal iniciativa partir do empregado, criando a figura do teletrabalho eventual.

Da mesma consulta realizada no Sistema Mediador retromencionada, onze negociações coletivas trazem a previsão do teletrabalho eventual, assim conceituado:

"O Teletrabalho Eventual é aquele que ocorre de forma não programada, em virtude de solicitações pontuais do EMPREGADO ou de situações emergenciais, tais como paralisação de transporte público, bloqueio de vias de acesso, condições climáticas, etc, devidamente analisadas e aprovadas pelo gestor imediato. No teletrabalho eventual o EMPREGADO mantém todos os seus benefícios, inclusive o vale transporte quando ordinariamente fornecido".

O que se nota é que este teletrabalhador eventual é na verdade um trabalhador hídrido (presencial e teletrabalhador) cujos direitos fundamentais devem ser os mesmos do trabalhador celetista normal. Corre-se o risco, se isto não for reconhecido, de deixar este teletrabalhador à mercê de uma desproteção, ao não se reconhecer a ele um status nem de teletrabalhador, nem de trabalhador a domicílio. Veja-se que o trabalhador à domicílio segundo a OIT é o que habitualmente trabalha em casa, segundo Convenção 177. Também a Recomendação 184 da OIT dispõe que a ocasionalidade desconfigura o trabalho a domicílio. Por isso no pós-pandemia urge a necessidade em falar-se e de regular o teletrabalho, o que, aliás, já foi feito pela legislação mexicana ${ }^{32}$.

32 OPERAMUNDI. México aprova lei para que empresas paguem luz e internet de trabalhador em home office. [Consultado em: 12/12/2020]. Disponível em: https://operamundi.uol.com.br/politica-e-economia/67779/mexico-aprova-lei-para-que-empresas-paguem-luz-e-internet-de-trabalhador-em-home-office 


\section{DIREITOS FUNDAMENTAIS DO TELETRABALHADOR EM TEMPOS DE PANDEMIA}

Teses de constitucionalistas afirmam que o período que vivemos todos os direitos fundamentais se reorganizam em torno da supremacia do interesse público que é a manutenção da saúde do trabalhador ${ }^{33}$. Ou seja, o direito social à saúde passa momentaneamente na frente dos demais direitos, por Medidas provisórias que atendem a necessidade e correspondem aos requisitos de relevância e urgência, previstos na Constituição Federal. A pandemia na legislação que lhe regula não suprime as garantias do trabalho contidas no arts. $6 .^{\circ}, 7^{\circ}$ e $8 .^{\circ}$ da Constituição Federal, além das garantias individuais, as quais são reputadas como direitos inespecíficos do trabalhador, aqueles que possui como cidadão.

Importante sinalizar, que o teletrabalho, em tempos de pandemia, encontrou um teletrabalhador de emergência, despreparado. Por isso é necessário frisar que o momento admite excluir-se um trabalhador que esteja despreparado para o teletrabalho, podendo o empresário remetê-lo a outros mecanismos de manutenção de renda, como férias, suspensão do contrato, banco de horas. Ao contrário, alguns estarão aptos a serem incluídos, e até mesmo uma série de ocupados vulneráveis teriam a chance de serem incorporados, ainda que transitoriamente, em trabalhos temporários, conforme refere a OIT.

Para OIT a vivência da humanidade neste momento é de um desastre e, mesmo nesta situação, aponta para a necessidade de que se tenha como meta o trabalho decente. Vale recordar o conceito de trabalho decente no âmbito da OIT: O trabalho decente é definido como "aquele desenvolvido em ocupação produtiva, justamente remunerada e que se exerce em condições de liberdade, eqüidade, seguridade e respeito a dignidade da pessoa humana ${ }^{34 "}$.

Recentemente, atualizando este conceito, a OIT emitiu a Recomendação 205 - Recomendação de emprego e trabalho decente para a paz e a resiliência, 2017 (n. $\left.{ }^{\circ} 205\right)$, considerando o impacto e as consequências que os conflitos e desastres têm sobre pobreza e desenvolvimento, direitos humanos e dignidade, trabalho decente e negócios sustentáveis. Por este documento, Recomendação 205 da OIT, a situação vivenciada por todo o mundo referente à pandemia pode ser classificada como um desastre em proporções globais que não dispensa a proteção dos trabalhadores. Para a OIT "o termo "desastre" designa uma perturbação grave do funcionamento de uma comunidade ou sociedade em qualquer escala,

33 SARLET, Ingo - Direitos Fundamentais e Democracia em tempos de pandemia. [Consultado em: 01/05/2020]. Disponível em: http://fcr.edu.br/direitos-fundamentais-e-democracia-em-tempos-de-pandemia-e-tema-de-live-promovida-pela-faculdade-catolica-de-rondonia/

34 ORGANIZAÇÃO INTERNACIONAL DO TRABALHO - Documento GB 280/wp/sdg/1, de março de 2001. [Consultado em: 29/04/2020]. Disponível em: http://www.ilo.org 
devido a fenômenos perigosos que interagem com as condições de exposição, vulnerabilidade e capacidade, causando um ou mais dos seguintes fatores: perdas e impactos humanos; materiais, econômicos e ambientais;" já o "termo 'resiliência' designa a capacidade de um sistema, comunidade ou sociedade exposta a uma ameaça de resistir, absorver, adaptar, transformar e recuperar seus efeitos de maneira oportuna e eficiente, principalmente através da preservação e restauração de suas estruturas e funções básicas através do gerenciamento de riscos".

A OIT refere que epidemias e crises econômicas podem ter um impacto desproporcional em certos segmentos da população ${ }^{35}$. Desencadeia-se, provavelmente, neste contexto, o agravamento da desigualdade. Com base em experiências anteriores e informações atuais sobre a pandemia do COVID-19, vários grupos de trabalhadores seriam potencialmente identificados como possíveis incluídos pelo teletrabalho, a partir de um recurso de capacitação. Listamos alguns, segundo nosso entendimento, os quais seriam candidatos a serem aproveitados, pelo acréscimo de demanda de trabalho tecnológico no momento da pandemia ${ }^{36}:$ a) aqueles empregados com condições de saúde precárias e idosos com maior risco de desenvolver sérios problemas de saúde; b) os jovens, que já enfrentam taxas mais altas de desemprego e subemprego, os quais são mais vulneráveis à queda da demanda de trabalho, como testemunhado durante a crise financeira global; c) as mulheres que estão presentes em setores mais afetados (como serviços) ou em ocupações que estão na linha de frente de lidar com a pandemia (por exemplo, enfermeiras); d) trabalhadores desprotegidos, incluindo trabalhadores independentes, casuais, informais, os quais serão provável e desproporcionalmente atingidos pelo vírus, pois não têm acesso a mecanismos de licença remunerada ou por doença e são menos protegidos por mecanismos convencionais de proteção social e outras formas de renda, mas poderão ser incorporados em serviços temporários; e e) os trabalhadores migrantes, os quais são particularmente vulneráveis ao impacto da crise do COVID-19, que restringirá sua capacidade de acessar seus locais de trabalho nos países de destino e retornar para suas famílias.

A inclusão de mulheres, idosos, de pessoas com deficiência e jovens no mercado de trabalho poderá ser uma realidade para as economias que adotarem o regime de teletrabalho como atividade central para o período de pandemia.

35 BARZOTTO, L.. C. ; RECKZIEGEL, T. - Coronavírus e OIT- Organização Internacional do Trabalho. In: Ricardo Calcini. (Org.). Coronavírus e OIT. 1ed. São Paulo: JH Mizuno, 2020, v. 1, p. 7505-7679.

36 ORGANIZAÇÃO INTERNACIONAL DO TRABALHO - Como o COVID-19 afetará o mundo do trabalho? [Consultado em: 29/04/2020]. Disponível em: https://www.ilo.org/global/topics/coronavirus/impacts-and-responses/WCMS_739047/lang--en/index.htm 
A ampla adoção dessa estratégia no atual momento, apresenta-se mais como um elemento de aceleração de um processo já em curso, de digitalização da economia diante da chamada indústria 4.0, do que como um evento situacional, por isso importante a manutenção de suas bases de trabalho decente. Por isso é interessante que se contemplem garantias fundamentais ou direitos fundamentais para estes prestadores de serviços telemáticos.

A adoção do teletrabalho por um número tão grande de trabalhadores, especialmente de maneira tão repentina, exigiu diversas adaptações por parte não somente dos empregados, mas também dos empregadores. Inicialmente, pode excluir do trabalho aqueles que estiverem despreparados, ao invés de ser forma de inclusão. Para o uso de meios telemáticos, Aguiar explica que as mudanças decorrentes da tecnologia, de velocidade incrível, devem encontrar as relações de trabalho capazes de se adaptar, envolvendo empregadores e empregados. Necessita-se de uma capacitação transversal, como um processo de complementação multifuncional de desenvolvimento profissional obrigatório para enfrentamento dessas novas alterações funcionais ${ }^{37}$. Não houve, entretanto, tempo suficiente para esta passagem, no período de pandemia, embora o teletrabalho tenha vindo para ficar.

Além do problema da formação emergencial do teletrabalhador, os outros direitos sociais, como moradia, alimentação, lazer, que devem ser garantidos pelo Estado, em primeiro lugar, clamam pela participação subsidiária do setor privado, sobrecarregando-se de demandas. Verifica-se que, para o exercício do teletrabalho, o qual transformou-se em trabalho em domicílio, reinventam-se os lares, os quais se tornaram espaços públicos/privados, espécie de coworking de famílias e empresas, nos quais os pais tem que regular suas atribuições e garantir educação, saúde, alimentação aos seus dependentes, neste espaço confinado. Isso exige uma reorganização dos espaços e tempos, para o que a OIT indica a urgência de divisão equânime de tarefas e responsabilidades familiares, para que o espaço da microeconomia seja compatível com o mundo laboral, conforme orienta a Convenção 146, e Convenções 100 e 111.

Neste espaço doméstico do teletrabalhador podem conviver pessoas que ficam impactadas de forma diferente pelas restrições sociais. Ainda que trabalhando em ambiente virtual com colegas, estamos participando de uma experiência presencial e conjunta com os familiares os quais se tornam espécie de colegas nem sempre colaborativos. A partir experiência do confinamento, e, especialmente pela pandemia do COVID-19, deve-se repensar a saúde mental de todos, mas em especial, de um outro grupo de pessoas, as que vivem sós. Conforme Hold-Lustad ${ }^{38}$, o isolamento social atua como fator de risco extremamente danoso 
para o adoecimento da população em geral, em função da invisibilidade do trabalhador. O isolamento reflete na ocupação ativa e no trabalho feito em casa de forma remota em períodos normais e isto acentua-se no período de calamidade pública declarado pela OMS.

Outros problemas, além da educação para o teletrabalho e a reorganização do espaço privado do lar como espaço social do trabalho, podem ser apontados pela dificuldade de garantia de alguns direitos previstos na Constituição, no art. $7 .^{\circ}$, como os incisos XXI e XXVII. O art. $7 .^{\circ}$, inciso XXII prevê a redução dos riscos inerentes ao trabalho por meio de normas de saúde, higiene e segurança. Quanto aos riscos, temos a dificuldade de garantir ao teletrabalhador a fiscalização do trabalho, mas também uma obrigação de todos de zelar pelo meio ambiente do trabalho. Como fazer isso no espaço da vida privada? $\mathrm{O}$ art. $7 .^{\circ}$, inciso XXVII prevê a proteção em face da automação, na forma da lei. Para o período do isolamento há os problemas da desconexão e limitação de jornada. Quanto à esta proteção em relação à automação temos um risco, para um período pós-pandemia, de que o empregador descubra formas que prescindam do empregado teletrabalhador. E aqui, na ausência de lei que garanta ao teletrabalhador proteção em face da automação está o risco de desemprego futuro deste.

Ainda outros direitos fundamentais devem ser lembrados e protegidos. A Constituição Federal prevê, em seu art. $5 \cdot^{\circ}$, parágrafo X, serem invioláveis "a intimidade, a vida privada, a honra e a imagem das pessoas, assegurado o direito a indenização pelo dano material ou moral decorrente de sua violação, por isso o direito aos dados do empregado e da invasão do lar fora dos momentos ajustados deve ser observada. Neste sentido, a Constituição Federal, seu art. $5 .^{\circ}, \mathrm{XII}$, também dispõe ser "inviolável o sigilo da correspondência e das comunicações telegráficas, de dados e das comunicações telefônicas, salvo, no último caso, por ordem judicial (...)".

Na França temos a discussão do uso do domicílio pelo teletrabalho e também do ponto de vista dos direitos fundamentais há um direito de retirada que é o empregado negar-se a trabalhar se houver perigo grave e iminente para a vida e saúde.

Em Portugal o teletrabalho pode ser pedido por qualquer uma das partes da relação de emprego. E, na família, o teletrabalhador pode ter apoio financeiro do Estado para cumular o cuidado com os filhos.

O Ministro do Trabalho alemão, Hubertus Heil, afirmou que pretende inserir na legislação da Alemanha o direito de trabalhar em casa após a pandemia. Ou seja, haverá um direito ao teletrabalho. $\mathrm{O}$ avanço do teletrabalho, que já era tido como algo quase que certo para o futuro do trabalho, conforme documentos da OIT, parece que foi impulsionado pela situação atual. ${ }^{39}$

39 BURKE, Jackson - As working from home becomes more widespread, many say they don't want to go back. [Consultado em: 29/04/2020]. Disponível em: https://www.cnbc.com/2020/04/24/as-working-from-home-becomes-more-widespread-many-say-they-dont-want-to-go-back.html Importante também destacar a 
Portanto, recorda-se que o período de desastre global não autoriza a dispensa de proteção do teletrabalhador, o qual merece um trabalho decente em período de crise.

\section{A IMPORTÂNCIA DA NEGOCIAÇÃO COLETIVA}

O crescente aumento do uso do teletrabalho como forma de prestação laboral tem exigido uma regulamentação minuciosa por parte do ordenamento jurídico. Na falta de uma legislação específica, segundo Fincato e Bublitz ${ }^{40}$, encontra-se na negociação coletiva o instrumento mais eficaz na realidade brasileira para preencher as lacunas legislativas a respeito da regulamentação do teletrabalho, trazendo segurança jurídica aos empregados e empregadores em seu relacionamento. $\mathrm{O}$ direito comparado nos traz a experiência do Acordo Marco Europeu sobre Teletrabalho, ${ }^{41}$ que estabeleceu o marco geral e mínimo sobre esta forma de prestação de trabalho no âmbito europeu.

Apesar de ser de adesão voluntária dos Estados membros da Comunidade, o acordo tem sido utilizado por vários países da Europa, assim como por entidades de representação trabalhista e patronal nas negociações coletivas, como norte para o estabelecimento das relações de teletrabalho. Cita-se particularmente a Itália como um bom exemplo de complementação da legislação sobre teletrabalho via negociação coletiva, que rege a matéria pelo chamado Acordo Interconfederativo, de 9 de Junho de 2004, e que também tem como norte o Acordo Marco Europeu ${ }^{42}$.

A Convenção 154 da OIT,43 em seu artigo $2^{\circ}{ }^{\circ}$, compreende a expressão negociação coletiva como todas as negociações entre uma parte, um empregador, um grupo de empregadores ou uma organização ou várias organizações de empregadores, e, de outra parte, uma ou várias organizações de trabalhadores, com fim de: a) fixar as condições de trabalho e emprego; ou b) regular as relações entre empregadores e trabalhadores; ou c) regular as

entrevista de um Ministro Alemão que apoia a lei a fim de incentivar o trabalho em casa. Disponível em: https:// abcnews.go.com/Business/wireStory/german-minister-backs-creating-legal-work-home-70351904. Consultado em: 29/04/2020.

40 FINCATO, Denise Pires; BUBLITZ, Michelle Dias - A negociação coletiva como ferramenta regulamentadora de norma aberta: o teletrabalho e a lei 12.551/2011. In: Revista Do Direito UNISC, Santa Cruz do Sul n. ${ }^{\circ}$. 44, set-dez 2014, p.127.

41 CONFEDERACIÓN EUROPEA DE SINDICATOS - Acuerdo Marco Europeo sobre Teletrabajo. [Consultado em: 29/04/2020]. Disponível em: https://www.ccooservicios.es/archivos/bbva/20110727_acuerdo_marco_europeo_ teletrabajo.pdf

42 FINCATO, Denise Pires; BUBLITZ, Michelle Dias - A negociação coletiva como ferramenta regulamentadora de norma aberta: o teletrabalho e a lei 12.551/2011. In: Revista Do Direito UNISC, Santa Cruz do Sul n. ${ }^{\circ}$. 44, set-dez 2014, p.122-128.

43 ORGANIZAÇÃO INTERNACIONAL DO TRABALHO - Convenção n. 154 - Fomento à Negociação Coletiva. [Consultado em: 19/07/2018]. Disponível em: http://www.ilo.org. 
relações entre os empregadores ou suas organizações e uma ou várias organizações de trabalhadores, ou alcançar todos estes objetivos de uma só vez.

No âmbito brasileiro, a negociação coletiva se apresenta como a opção mais articulada para que seja estabelecida a regulação da matéria. A inserção do teletrabalho no rol do artigo 661-A certamente é um indício desta opção para a criação de mecanismos como forma de solucionar ou minimizar as questões controvertidas que forem surgindo, conforme as necessidades das categorias profissionais, especialmente quando este dispositivo legal prevê a prevalência da negociação sobre a lei, ainda que não criada.

Em um mundo anterior à pandemia do COVID-19, o desafio residia exatamente no fato de que o teletrabalhador encontra-se em situação de maior vulnerabilidade por estar distanciado da coletividade de classe. Conforme Stürmer ${ }^{44}$, a atividade e a dinâmica sindical perderiam espaço ao não poder identificar os postos e locais de trabalho onde seus representados exercem suas atividades. O Acordo Marco Europeu aparenta ter pensado em uma solução, ao prever em seu item 11 que seja informado às representações sindicais acerca da introdução do regime de teletrabalho. A toda evidência, convém aos sindicatos a aproximação com seus representados e a sua integração e sentimento de pertencimento à categoria profissional, uma vez que, segundo o próprio item 11, o teletrabalho não pode ser obstáculo para a comunicação com as representações sindicais.

Por outro lado, a pandemia do COVID-19 que acometeu o mundo transformou rapidamente as relações de trabalho diante da necessidade de se laborar em regime de teletrabalho, devido à efetivação do isolamento social como forma de prevenção e contenção do vírus. A internet deixou de ser uma ferramenta de distanciamento para proporcionar o contato social e familiar em tempos de pandemia, ainda que de forma telemática. De igual modo, trabalhadores passaram a utilizar espaços virtuais para se encontrar com colegas de trabalho e executar as suas atividades.

Em consulta ao Sistema de Negociações Coletivas de Trabalho - MEDIADOR ${ }^{45}$, do Ministério do Trabalho e Emprego, foram localizados 210 instrumentos coletivos registrados no período de 11/03/2020 a 30/04/2020 e vigentes, cujo título constasse a palavra "teletrabalho". Foi escolhida a data inicial de 11/03/2020 por se tratar do dia em que a OMS declarou a pandemia de Coronavírus.

44 STÜRMER, Gilberto. Relações Coletivas e Teletrabalho - In: IV CONGRESSO IBERO-AMERICANO DE TELETRABALHO E TELEATIVIDADES PORTO ALEGRE. Anais do IV congresso ibero-americano de teletrabalho e teleatividades. Porto Alegre: Lex Magister, 2011, p. 73.

45 MINISTÉRIO DO TRABALHO E EMPREGO - Sistema de Negociações Coletivas de Trabalho - MEDIADOR. [Consultado em:30/04/2020]. Disponível em: http://www3.mte.gov.br/sistemas/mediador/ 
Destes, 8 (oito) instrumentos foram registrados no período de 11/03/2020 a 21/03/2020, mas apenas 3 (três) dizem respeito a termos aditivos celebrados para iniciar o regime de teletrabalho especificamente em razão da pandemia do COVID-19, expressamente mencionando este fato. Tratam-se de aditivos à convenções coletivas de trabalho, celebradas, portanto entre os sindicatos dos empregadores e dos empregados, todos situados no Estado do Rio Grande do Sul, registrados em 17/03/2020 e 19/03/2020. Embora pequeno o número, o dado é importante, pois revela a percepção e o diálogo entre as coletividades para a preservação e garantia do direito fundamental à vida, à saúde, de forma conciliada com o direito ao trabalho, ambos direitos fundamentais do trabalhador, antes mesmo da promulgação da MP 927.

Conforme previsto pela MP 927, ainda que seja unilateral a determinação de home office, alguns doutrinadores têm apontado que verbas como auxílio-alimentação, convênios e auxílios como creches só poderiam ser retirados pela negociação coletiva revisada, caso decorra dela estes direitos. Também seria interessante se a negociação coletiva previsse cláusulas que determinem que o empregador arque com os custos de utilização de luz, telefone e outras adaptações funcionais do teletrabalho.

Convém lembrar que o artigo $11, \S 4 .^{\circ}$, da MP 936, que impõe expressamente que os acordos individuais celebrados na MP 927, inclusive sobre questões de teletrabalho, "deverão ser comunicados pelos empregadores ao respectivo sindicato laboral, no prazo de até dez dias corridos, contado da data de sua celebração". Neste sentido, alguns doutrinadores entendem que a obrigação de submeter o acordo individual ao sindicato [...] "integra a própria essência do acordo individual, já que foi a forma encontrada pelo governo para evitar a inconstitucionalidade dos acordos individuais, por afronta ao artigo 7. ${ }^{\circ}$, VI, da Constituição", como menciona Cesar Zucatti Pritsch ${ }^{46}$.

Apesar das divergências motivadas pela MP 936, que restringiu o papel negocial dos sindicatos durante a crise do Coronavírus, e da decisão liminar do E. STF na ADI n. 6.363, que havia decidido, num difícil exercício de equilíbrio entre atuação sindical e governamental, pela necessidade da anuência sindical nos contratos individuais firmados entre empregado e empregador para redução de jornada e salário, parece que a mais adequada negociação na crise do Coronavírus é com a participação sindical, a qual, aliás, é incentivada pela interpretação do art. 2 da MP $927^{47}$.

46 PRITSCH, Cesar Zucatti - MP 936: acordos individuais impedem a atuação dos sindicatos? [Consultado em: 29/04/2020]. Disponível em: https://www.conjur.com.br/2020-abr-28/pritsch-acordos-individuais-impedem-atuacao-sindicatos.

47 MELO, Raimundo Simão de. Negociações coletivas na crise do Coronavírus. Disponível em: https://www.conjur. com.br/2020-abr-17/negociacoes-coletivas-crise-coronavirus. Consultado em: 29/04/2020. 
Aliás cumpre lembrar que sindicatos profissionais e econômicos ${ }^{48}$, na crise do Coronavírus podem e devem exercer o diálogo social fixando tempo, horário e remuneração, mediando o afastamento presencial de trabalhadores de grupos de risco como por exemplo, pessoas com idade superior a 60 anos, com deficiência, doenças degenerativas, dentre outras.

Se houver banco de horas para o teletrabalho, ou mesmo fixação regular de jornada, como alguns admitem para efeitos da MP 936, seria importante a atuação sindical para a sua fixação. Isso porque a lei não veda redução de jornada e salários inclusive para o teletrabalhador, a partir da interpretação da MP 936 e da Portaria 10.486 que regula o BEM (benefício emergencial). Ainda que o teletrabalhador fosse receber férias coletivas, seria interessante o sindicato se fazer presente, nos termos da previsão do art. 139 da CLT e mesmo que o art. 11 da MP 927 o dispense. Indicação semelhante é feita para o vale-transporte e alimentação, para o adiantamento do período de férias, para a flexibilização de horários, e para as normas de saúde, segurança e medicina do trabalho, reguladas no art. 154 e ss. da CLT. O trabalho em casa, por meio remoto e digital, deverá ser privilegiado, e novas plataformas de trabalho deverão ser desenvolvidas, sendo que o sindicato pode e deve atuar neste novo cenário.

Na rede mundial de computadores assiste-se tendências opostas; isolacionismo ou uma nova consciência fraterna, a qual vem se formando ${ }^{49}$, com mais velocidade e ímpeto a ser visto pelas ações concretas de solidariedade para com os atingidos pela pandemia. A experiência conjunta do isolamento social alavancou a implementação do regime de teletrabalho, que certamente não será mais a mesma após a epidemia. Novas formas de se relacionar e de laborar de modo não presencial estão se desenvolvendo, superando as dificuldades impostas pelo afastamento, que certamente refletirão nas relações coletivas.

Em um momento em que as próprias centrais sindicais estão realizando suas reuniões por videoconferência ${ }^{50}$, votações de assembleias, as negociações coletivas no contexto do teletrabalho revelam o debate atual de coordenação das ações sindicais com a nova reali-

48 SANTOS, Enoque Ribeiro dos - O Direito Coletivo do Trabalho em tempos de Coronavírus. [Consultado em: 29/04/2020]. Disponivel em: https://genjuridico.jusbrasil.com.br/artigos/822599511/o-direito-coletivo-do-trabalho-em-tempos-de-coronavirus.

49 Ver FINCATO, Denise Pires - O Valor Social do Trabalho e o Princípio da Fraternidade: Reflexões sobre o Teletrabalho. In Compedi Law Review. v. 1, n. 6, 2015, p. 105-128. Veja-se a também em FINCATO, Denise. O valor social do trabalho e o princípio da fraternidade: reflexões sobre o teletrabalho. In: GUEDES, Priscila Dal Ponte Amado; GUEDES, Gabriel Pinto; BARZOTTO, Luciane Cardoso (org.). Direito e fraternidade: em busca de respostas. Porto Alegre: Sapiens, 2016, pp. 76-78.

50 SINDICATO DAS METALÚRGICAS - MPT e Centrais sindicais debatem atuação conjunta em defesa da classe trabalhadora frente crise do Coronavírus. [Consultado em: 29/04/2020]. Disponível em: https://ctb.org.br/sem-categoria/formacao-sindical-ctb-inaugura-reuniao-por-videoconferencia-nesta-sexta/. 
dade na qual foi mergulhado o mundo. É conveniente ainda que os sindicatos aproveitem a experiência telemática para ensaiar práticas não apenas de regulamentação dos direitos dos teletrabalhadores, mas também de proteção e prevenção de conflitos e repressão condutas antissindicais que possam surgir no futuro próximo, relacionado ao teletrabalho.

Enquanto durar a necessidade de isolamento, ainda que de forma intermitente, as negociações coletivas acerca da implementação do teletrabalho ficam à disposição como instrumentos ágeis para regulamentar as particularidades de cada categoria econômica e social, e prometem ser importantes ferramentas para a efetivação massiva deste regime.

\section{CONCLUSÃO}

Parece que o resultado dos estudos do futuro do trabalho, levados a efeito pela OIT e que apontavam o teletrabalho como uma forma essencial de ocupação e renda para 2030, foi antecipado pelos tempos da epidemia global. A massiva contratação de trabalhadores em regime de teletrabalho e conversão de trabalhos presenciais nesta espécie de home office forçada poderá influenciar o futuro do trabalho, após a situação de surto, motivo pelo qual urge a sua regulamentação com maior detalhamento e cuidado.

Dentre os americanos que passaram a realizar o teletrabalho a partir da pandemia de COVID-19, 24\% dos entrevistados afirmaram que gostariam de continuar trabalhando em casa, de forma integral ou parcial, após a pandemia. Nessa mesma pesquisa, $60 \%$ dos entrevistados afirmam que sua produtividade está igual ou superior à de quando trabalhavam fora de casa.

Embora não tenhamos dados suficientes no Brasil, acredita-se que a introdução ao teletrabalho na América do Norte pode ter efeito bastante semelhante nos trabalhadores daqui, o que indica a ideia de permanência deste regime após a vigência do estado de calamidade e além da produtividade mencionada nas pesquisas, outros benefícios podem advir da exploração deste instrumental.

Ademais, empresas buscam alternativas para atuar no mercado de trabalho de um economia, a qual passa também por este desafio de se modificar, de se inovar, cooperar para a prosperidade, paz e resiliência de todos, encontrando no teletrabalho uma de suas melhores opções.

Nesse diapasão, o papel negocial dos sindicatos revela-se não apenas relevante do ponto de vista normativo, como ferramenta para a regulamentação dos direitos dos teletrabalhadores, como também do ponto de vista econômico e social, fomentando o diálogo e a pacificação entre empregados e empregadores, de modo a impulsionar o crescimento fraterno da sociedade em tempos tão difíceis. 


\section{VII. ÍNDICE BIBLIOGRÁFICO}

AGUIAR, Antonio Carlos - Direito do Trabalho 2.o digital e disruptivo. São Paulo: LTr, 2018.

BARZOTTO, L.. C. ; RECKZIEGEL, T. - Coronavírus e OIT- Organização Internacional do Trabalho. In: Ricardo Calcini. (Org.). Coronavírus e OIT. 1ed. São Paulo: JH Mizuno, 2020, v. 1, p. 7505-7679.

BARZOTTO, L. C.; LANNER, M. B - Fraternidade e trabalho digital na Constituição da Organização Internacional do Trabalho. In: I Congresso Internacional, Interinstitucional e Interdisciplinar de Pesquisadores em Direito e Economia, 2019, Belo Horizonte. Belo Horizonte: Universidade Federal de Minas Gerais, 2019.

BURKE, Jackson - As working from home becomes more widespread, many say they don't want to go back. [Consultado em: 29/04/2020]. Disponível em: https://www.cnbc.com/2020/04/24/as-working-from-home-becomes-more-widespread-many-say-they-dont-want-to-go-back.html

BRASIL - Consolidação das Leis do Trabalho - Decreto-Lei n. 5.452, de 1. ${ }^{\circ}$ de maio de 1943. [Consultado em: 25/05/2018]. Disponível em: http://www.planalto.gov.br

CARELI, Rodrigo - O teletrabalho. In: Resistência: aportes teóricos contra o retrocesso trabalhista. Coordenadores: Jorge Luiz Souto Maior, et alii. 1. ed. São Paulo: Expressão Popular: 2017.

CAVALCANTE, Jouberto de Quadros Pessoa; JORGE NETO, Francisco Ferreira - Uma reflexão sobre a "Subordinação" como elemento essencial da relação de emprego. In: CLT - 70 anos de Consolidação: Uma reflexão social, econômica e jurídica. Jouberto de Quadros Pessoa Cavalcante e Marcos Antônio Cesar Villatore (Organizadores). São Paulo: Atlas, 2013.

COMISSÃO DAS COMUNIDADES EUROPEIAS - Confederação Europeia dos Sindicatos (CES) a Confederação das Empresas Europeias (UNICE), o Centro Europeu das Empresas com Participação Pública e das Empresas de Interesse Económico Geral (CEEP); Associação Europeia de Artesanato, Pequenas e Médias Empresas (UEAPME). Relatório sobre a implementação do Acordo-Quadro sobre o Teletrabalho de 16 de julho de 2002. [Consultado em: 28/04/2020]. Disponível em: http://repertoriojuslaboral.blogspot.com

CONFEDERACIÓN EUROPEA DE SINDICATOS - Acuerdo Marco Europeo sobre Teletrabajo. [Consultado em: 29/04/2020]. Disponível em: https://www.ccooservicios.es/archivos/bbva/20110727_acuerdo_marco_ europeo_teletrabajo.pdf

FERREIRA, António Casimiro - Sociedade da austeridade: e direito do trabalho de exceção. Porto: Vida Económica, 2012.

FINCATO, Denise Pires - Teletrabalho na Reforma Trabalhista Brasileira. In: Revista Magister de Direito do Trabalho, n. ${ }^{\circ} 82$, Jan-Fev/2018.

FINCATO, Denise Pires; BUBLITZ, Michelle Dias - A negociação coletiva como ferramenta regulamentadora de norma aberta: o teletrabalho e a lei 12.551/2011. In: Revista Do Direito UNISC, Santa Cruz do Sul n. ${ }^{\circ}$. 44, set-dez 2014.

FINCATO, Denise Pires - O Valor Social do Trabalho e o Princípio da Fraternidade: Reflexões sobre o Teletrabalho. In Compedi Law Review. v. 1, n. 6, 2015, p. 105-128.

FINCATO, Denise - O valor social do trabalho e o princípio da fraternidade: reflexões sobre o teletrabalho. In: GUEDES, Priscila Dal Ponte Amado; GUEDES, Gabriel Pinto; BARZOTTO, Luciane Cardoso (org.). Direito e fraternidade: em busca de respostas. Porto Alegre: Sapiens, 2016.

EUROFOUND - Trabalhar a qualquer hora, em qualquer lugar e seus efeitos no mundo do trabalho. [Consultado em: 26/07/2018]. Disponível em: https://www.eurofound.europa.eu

HOLT-LUNSTAD, J.; SMITH, T. B.; LAYTON, J. B - Social Relationships and Mortality Risk: A Meta-analytic Review. PLoS Medicine, vol. 7, n. 7, 2010. e1000316. doi:10.1371/journal.pmed.1000316.

MELO, Raimundo Simão de - Negociações coletivas na crise do Coronavírus. [Consultado em: 29/04/2020]. Disponível em: https://www.conjur.com.br/2020-abr-17/negociacoes-coletivas-crise-coronavirus 
MINISTÉRIO DO TRABALHO E EMPREGO - Sistema de Negociações Coletivas de Trabalho - MEDIADOR. [Consultado em: 30/04/2020 e 22/08/2020]. Disponível em: http://www3.mte.gov.br/sistemas/mediador/ MIZIARA, Raphael; UMBERTO, Antonio; COELHO, Fabiano; GASPAR, Danilo - Medida Provisória 927 de 2020: comentários artigo por artigo. São Paulo: Revista dos Tribunais - Thomson Reuters, 2020.

NILLES, Jack M - Fazendo do teletrabalho uma realidade: um guia para telegerentes e teletrabalhadores. Tradução Eduardo Pereira e Ferreira. São Paulo: Futura, 1997.

OLIVEIRA, Murilo Carvalho Sampaio - Relação de emprego, dependência econômica e subordinação jurídica: revisitando os conceitos - critérios de identificação do vínculo empregatício. Curitiba: Juruá, 2014.

OPERAMUNDI. México aprova lei para que empresas paguem luz e internet de trabalhador em home office. [Consultado em: 12/12/2020]. Disponível em: https://operamundi.uol.com.br/politica-e-economia/67779/ mexico-aprova-lei-para-que-empresas-paguem-luz-e-internet-de-trabalhador-em-home-office

ORGANIZAÇÃO INTERNACIONAL DO TRABALHO - Convenio sobre el trabajo a domicilio, 1996 (núm. 177). [Consultado em: 27/06/2019]. Disponível em: http://www.ilo.org

ORGANIZAÇÃO INTERNACIONAL DO TRABALHO - Convenção n. 154 - Fomento à Negociação Coletiva. [Consultado em: 19/07/2018]. Disponivel em: http://www.ilo.org

ORGANIZAÇÃO INTERNACIONAL DO TRABALHO - Notas da OIT, trabalho e família n.5: Alternativas que podem facilitar a conciliação entre o trabalho e a família. [Consultado em: 25/02/2018]. Disponível em: http://www.ilo.org

ORGANIZAÇÃO INTERNACIONAL DO TRABALHO - Como o COVID-19 afetará o mundo do trabalho? [Consultado em: 29/04/2020]. Disponível em: https://www.ilo.org/global/topics/coronavirus/impacts-and-responses/WCMS_739047/lang--en/index.htm

ORGANIZAÇÃO INTERNACIONAL DO TRABALHO - Documento GB 280/wp/sdg/1, de março de 2001. [Consultado em: 29/04/2020]. Disponível em: http://www.ilo.org

ORGANIZAÇÃO INTERNACIONAL DO TRABALHO E EUROFOUND - Relatório "Trabalhando a qualquer hora, em qualquer lugar: os efeitos no mundo do trabalho". [Consultado em: 26/07/2018]. Disponível em: http://www.ilo.org

PRITSCH, Cesar Zucatti - MP 936: acordos individuais impedem a atuação dos sindicatos? [Consultado em: 29/04/2020]. Disponível em: https://www.conjur.com.br/2020-abr-28/pritsch-acordos-individuais-impedem-atuacao-sindicatos

RAMALHO, Maria do Rosário Palma - Estudo de Direito do Trabalho. V. 1. Livraria Almedina, Coimbra: 2003. RIFKIN, Jeremy - The zero marginal cost society: the internet of things, the collaborative commons, and the eclipse of capitalism. New York: Palgrave Macmillan. 2014.

SAP CONSULTORIA EM RECURSOS HUMANOS - Pesquisa Home Office Brasil 2018. [Consultado em: 08/01/2019]. Disponível em: https://sapconsultoria.com.br.

SARLET, Ingo - Direitos Fundamentais e Democracia em tempos de pandemia. [Consultado em: 01/05/2020]. Disponível em: http://fcr.edu.br/direitos-fundamentais-e-democracia-em-tempos-de-pandemia-e-tema-de-live-promovida-pela-faculdade-catolica-de-rondonia/

SANTOS, Enoque Ribeiro dos - O Direito Coletivo do Trabalho em tempos de Coronavírus. [Consultado em: 29/04/2020]. Disponível em: https://genjuridico.jusbrasil.com.br/artigos/822599511/o-direito-coletivo-do-trabalho-em-tempos-de-coronavirus.

SINDICATO DAS METALÚRGICAS - MPT e Centrais sindicais debatem atuação conjunta em defesa da classe trabalhadora frente crise do Coronavírus. [Consultado em: 29/04/2020]. Disponível em: https:// ctb.org.br/sem-categoria/formacao-sindical-ctb-inaugura-reuniao-por-videoconferencia-nesta-sexta/. 
SIQUEIRA, Rodrigo Espiúca dos Anjos - A duração do trabalho na Lei 13.467/2017. In: Reforma trabalhista na visão acadêmica. Gilberto Stümer e Leandro do Amaral Dorneles de Dorneles (Organizadores). Porto Alegre: Verbo Jurídico, 2018.

STÜMER, Gilberto - Relações Coletivas e teletrabalho. In: IV Congresso Ibero-Americano de teletrabalho e Teleatividades. Porto Alegre: Magister, 2011.

STÜRMER, Gilberto - Relações Coletivas e Teletrabalho. In: IV CONGRESSO IBERO-AMERICANO DE TELETRABALHO E TELEATIVIDADES PORTO ALEGRE. Anais do IV congresso ibero-americano de teletrabalho e teleatividades. Porto Alegre: Lex Magister, 2011.

WINTER, Vera Regina Loureiro - Teletrabalho: Uma forma alternativa de emprego. São Paulo: LTr, 2005. 